\title{
A retrospective observational study of intraductal breast papilloma and its coexisting lesions: a real- world experience
}

\section{Xiaoyun Mao}

the 1st affiliated hospital of China Medical University

Huan Wang

the 1st affiliated hospital of China Medical University

Zhe Sun

the 1st affiliated hospital of China Medical University

Chuifeng Fan

China Medical University

Feng Jin ( $\nabla_{\text {jf2618@126.com ) }}$

the 1st affiliated hospital of China Medical University

Research article

Keywords: intraductal breast papilloma, real-world experience

Posted Date: September 6th, 2019

DOI: https://doi.org/10.21203/rs.2.14000/v1

License: (9) This work is licensed under a Creative Commons Attribution 4.0 International License.

Read Full License 


\section{Abstract}

Background: Breast intraductal papilloma are a heterogeneous group. The aim of this study is to investigate the intraductal breast papilloma and its coexisting lesions retrospectively in real-world practice.

Methods: We retrospectively identified 4450 intraductal breast papilloma and its coexisting lesions.

Results: $18.36 \%$ coexisted with malignant lesions of the breast, $37.33 \%$ coexisted with atypia hyperplasia, $25.24 \%$ coexisted with benign lesions and only $19.10 \%$ coexisted without concomitant lesions. In addition, $36.80 \%$ of intraductal breast papilloma had nipple discharge, $51.46 \%$ had a palpable breast mass and $16.45 \%$ had both nipple discharge and a palpable breast mass. $28.18 \%$ experienced discomfort or were asymptomatic. Furthermore, $98.99 \%$ had ultrasound abnormalities, $53.06 \%$ had intraductal hypoechoic upon ultrasound. $31.89 \%$ had mammographic distortion, $14.45 \%$ had microcalcification upon mammography. Intraductal breast papilloma with malignancy had significant correlations with clinical manifestations.

Conclusion: Coexisting malignancy was also related to ultrasound abnormality (BIRADS 4C and 5), mammographic distortion and microcalcification upon mammography but was not related to the intraductal hypoechoic upon ultrasound. Coexisting atypical hyperplasia correlated with nipple discharge but not palpable mass, mammographic distortion or intraductal hypoechoic upon ultrasound. The coexisting atypia hyperplasia was also related to abnormality upon ultrasound or microcalcification compared with the benign lesions. The intraductal papilloma coexists with malignancy or atypia hyperplasia accounted for more than $50 \%$, the clinical information on papilloma and its coexisting lesions is nonspecific. We recommended surgical treatment for benign intraductal papillary lesions. Impact: The current study provides insight into the real-world pattern of intraductal papillomas and their coexisting lesions in a population of Chinese women.

\section{Introduction}

An intraductal papilloma is a benign, or noncancerous breast tumor which originated from the epithelium of mammary ducts that forms in a milk duct. A fibrovascular stroma supported both the luminal epithelial and the outer myoepithelial cell layers for the formation of epithelial fronds, which is a characteristic of the intraductal papilloma ${ }^{[1]}$. The morphologic changes of epithelial component include from metaplasia to hyperplasia, atypical intraductal hyperplasia, or in situ carcinoma ${ }^{[2]}$. The symptoms, clinical signs and supersonical appearances widely differ. These lesions may present clinically either as ultrasound abnormalities or palpable breast masses, with or without nipple discharge. Central papilloma originates from large ducts, often accompanied by pathological nipple discharge, while most peripheral papillomas occur in TDLU, involving small ducts. ${ }^{[3,4]}$. The prognosis and treatment of papillomas have been influenced by views on their "precancerous" potential, and papillomas can harbor occult atypia hyperplasia or carcinomas. The management of benign intraductal papilloma remains controversial 
because of its nonspecific clinical findings, as well as its association with surrounding malignant pathology ${ }^{[5-7]}$. Herein, we present the results from an observational study carried out according to a retrospective design. Our study aimed to address intraductal breast papilloma and its coexisting lesions.

\section{Study Design}

In this study, patients with intraductal papilloma of the breast who underwent surgical resection in the first affiliated Hospital of China Medical University from November 1999 to July 2017 were analyzed retrospectively. During the period of 18-year, a total of 5,708 women were examined. Two pathologists whose subspecialty focus on breast lesions, reviewed each case independently. Only those cases where both pathologists had the same diagnosis can be used. Of those, 4,450 cases were eligible and selected into the research queue, according to the criteria of agreement and ethical approval. We reviewed the clinicopathological data of each patient. The patients before 2010 Feb weren't sign informed consent due to the exemption of the retrospective format. All patients after February 2010 involved in the study signed informed consent to participate in the study and agreed to publish the results.

\section{Patients}

We retrospectively identified 4450 intraductal breast papilloma patients with surgical excision from November 1999 through July 2017 at the First Affiliated Hospital of China Medical University. The patients' ages ranged from 13 to 88 , with an average age of $47.86 \pm 11.93$ years.

\section{The Concomitant Lesion Of The Breast}

We classified all pathological types of breast lesions according to World Health Organization standards published by Tavassoli FA et al. ${ }^{[8,9]}$. A comprehensive list of pathologic features was reviewed, including margins whose tissue-free ranges were defined as $<15 \mathrm{~mm}$; concomitant adenosis; atypia hyperplasia $(\mathrm{AH}$, including atypia ductal hyperplasia and atypia lobular hyperplasia); ductal or lobular carcinoma in situ; invasive ductal cancer and other malignancies.

\section{Statistical Analysis}

All the statistical analyses were descriptive in nature. The independent two-sample $t$-test was performed to evaluate continuous categorical variables between benign, atypical and malignant lesions. The chisquare or Fisher's exact tests were used for comparing categorical variables. One-way ANOVA was used to identify the association between different groups and patients' age. A $p$ value $<0.05$ was considered statistically significant.

\section{Ethics}


The research was reviewed and approved by the Ethics Committee of China Medical University and its first affiliated hospital. All of the methods were performed in accordance with the Declaration of Helsinki and the relevant guidelines.

\section{Results}

A total of $18.36 \%(817 / 4450)$ of intraductal breast papilloma coexisted with malignant lesions of the breast, 37.30\% (1660/4450) coexisted with AH (including ADH and ALH), 25.24\% (1123/4450) coexisted with benign lesions, and only $19.10 \%$ (850/4450) coexisted without concomitant lesions, Figure 1. Figure 2 shows the papilloma and its coexisting benign lesions. Figure 3 shows the papilloma and its coexisting ductal carcinoma in situ. Figure 4 shows the typical papillocarcinoma. Figure 5 shows the papilloma and its coexisting invasive ductal carcinoma. For the coexisting benign lesions, 157 cases coexisted with fibroma. For the coexisting benign lesions, 157 cases coexisted with fibroma. The clinical symptoms of papilloma and its coexisting lesions including asymptomatic lesions, nipple discharge and a palpable mass are non-specific. A papilloma usually involves nipple discharge, which contains serous fluid sometimes or blood and both. In our results, $36.80 \%$ (1638/4450) of the intraductal breast papilloma had nipple discharge, $51.46 \%(2290 / 4450)$ had a palpable breast mass. A total of $16.45 \%(732 / 4450)$ had both nipple discharge and a palpable breast mass. In addition, 28.18\% (1254/4450) experienced discomfort in their breast or were asymptomatic, without nipple discharge or a palpable mass.

The radiological results of all the cases were recorded, ultrasonography and mammography results included. A total of $11.51 \%$ (512/4450) of patients did not have a mammography if they were $£ 35$ years old and had BIRADS 4A, confirmed by ultrasound abnormalities. In addition, $98.99 \%$ (4405/4450) had ultrasound abnormalities, and 53.06\% (2361/4450) had intraductal hypoechoic by ultrasound. Furthermore, 31.89\% (1256/3938) had mammographic distortion, and $14.45 \%$ (569/3938) had microcalcification upon mammograms.

In this cohort, the intraductal breast papilloma with malignancy was related to clinical manifestations, which contain a palpable breast mass ( $\mathrm{p}[0.01$ ), concurrent nipple discharge and a palpable mass $(p<0.01)$. Coexisting malignancy had significant correlations with ultrasound abnormality (BIRADS 4C and 5) $(p<0.01)$, but mammographic distortion and microcalcification upon mammograms had no correlations with intraductal hypoechoic by ultrasound, Table 1 .

In the subgroup of coexisting benign lesions and atypical lesions, coexisting atypical hyperplasia correlated with nipple discharge $(p<0.05)$ but did not correlate with a palpable mass $(p>0.05)$, mammographic distortion or intraductal hypoechoic by ultrasound $(p>0.05)$. Coexisting $\mathrm{AH}$ was also correlated with abnormalities found by ultrasound or microcalcification $(p<0.01)$ compared with the benign lesions, Table 2 .

In the concomitant malignancy of intraductal breast papilloma, $43.7 \%$ (357/817) were papillocarcinoma, $33.66 \%$ (275/817) were DCIS, 19.46\% (159/817) were invasive ductal cancer of the breast and $2.94 \%$ $(24 / 817)$ were another type. Figure 6 lists the types of coexisting malignancies. 


\section{Discussion}

Intraductal papillomas are benign tumors of the breast which arise from the epithelium of the lactiferous ducts (i.e., a system that links the lobules of the mammary gland with the tip of the nipple) ${ }^{[10]}$. Intraductal papillomas require histopathological confirmaion because it may turn out carcinogenesis ${ }^{[11}$, 12]. Studies have also shown that intraductal papilloma with atypia increases the risk of ductal carcinoma in situ (DCIS) or invasive breast cancer ${ }^{[13,14]}$. The treatment of breast intraductal papillomas has been controversial. Some advocate surgical resection of all lesions, despite benign pathological features, while others advocate removal only of specimens that are atypical or malignant. However, only a few studies have investigated this type of breast lesion and its coexisting cancers in Chinese women. We retrospectively reviewed 4450 intraductal papilloma of breast with surgical excision in Chinese women. The current study provides insight into the real-world pattern of intraductal papillomas and their coexisting lesions in a population of Chinese women.

Core needle biopsy (CNB) plays an important role in the diagnosis of breast lesions. This biopsy is usually performed earlier than any other treatment. CNB has limitations, such as the incomplete removal of the representative sampling of the target ${ }^{[15-17]}$. Published data was reviewed and provides estimates of the accuracy of percutaneous CNB and the upgrade to malignancy in diagnosing papillary breast lesions. Previous results strongly suggest that the diagnosis of intraductal papilloma by CNB should be surgical excision because a large number of lesions escalate into atypical lesions and malignant tumors at the time of resection. ${ }^{[18,19]}$. The data in these studies vary widely, especially in cases of intraductal papilloma with malignant tumors. Tabulated data from the investigations done by Mercado $\mathrm{CL}$ et al., are listed in Table 3. The literature contained data demonstrating papillomas with benign findings in approximately $72 \%$ of cases, with atypical ductal or lobular cells (ADH, ALH or LCIS) in approximately $14 \%$, and with DCIS or invasive carcinoma in approximately $13 \%$, which were diagnosed by CNB and subsequent surgical resection. Wen $\mathrm{X}$, et al recently reported a meta-analysis that contains 34 studies including 2236 nonmalignant breast papillary lesions at CNB were histologically reviewed after surgical resection ${ }^{[20]}$. In this research, $7.0-36.9 \%$ cases of benign papillomas were upgrade diagnosed as atypical papillary lesions and $15.7 \%$ cases of nonmalignant papillary lesions were upgrade diagnosed as malignancy. Three factors showed significant correlations with higher underestimation, including atypical papillary lesions $(P<0.001)$, positive mammographic results $(P=0.022)$, and published earlier than $2005(\mathrm{P}<0.05)$. Our study showed that $18.36 \%$ of intraductal papillomas coexist with malignancy, and $37.33 \%$ coexist with ADH, ALH or LCIS. The rate of coexistence with AH or LCIS is obviously higher than the rate previously indicated in Table 2. Most of the previous studies surveyed intraductal papilloma diagnosed with CNB and evaluated their potential coexisting risk of associated $\mathrm{AH}$ and malignancy, as identified by follow-up surgical excision. Some research excluded part of the data of intraductal papilloma coexisting with malignancy or AH diagnosed with CNB. The patients in our research had a diagnosed papilloma by surgical excision without CNB. The data were the real-world description data on intraductal papilloma and its coexisting lesions in China. If a patient had a diagnosed papilloma, she had 
an upgrade rate of $60 \%$ with $\mathrm{ADH}, \mathrm{ALH}$ or LCIS or with malignancy after undergoing surgical excision in China. Thus, we recommend surgically resect all benign intraductal papillary lesions as a more aggressive approach.

In our research, most women experienced asymptomatic lesions, pain or discomfort in their breast without nipple discharge or a palpable mass. If the recommended breast imaging indicated ultrasound abnormality or mammographic distortion, the risk assessment of breast malignancy was performed. If necessary, standard treatment for this condition involved surgery to remove the abnormality, especially the papilloma and the affected part of the milk duct. The diagnosed papilloma was removed by excision. The patient's demographics and clinical features were extracted and retrospectively reviewed from the medical records. The clinical presentation of ductal papilloma varied from asymptomatic, nipple discharge, palpable mass, breast pain or discomfort. Based on our data, $41.30 \%$ of intraductal breast papilloma had nipple discharge, $16.22 \%$ had a palpable breast mass, and $28.18 \%$ were asymptomatic or only had breast discomfort. In addition, intraductal breast papilloma with malignancy had significant correlations with clinical manifestations such as nipple discharge, a palpable breast mass, ultrasound abnormality (BIRADS 4C and 5), mammographic distortion and micro-calcification upon mammography. Clinical manifestations, supersonic findings and micro-calcification upon mammography were significantly associated with the coexisting lesions of malignancy. In our results, coexisting $\mathrm{AH}$ associated with nipple discharge, with abnormality by ultrasound or with micro-calcification upon mammography compared with the benign lesions. It is not easy to distinguish the coexisting benign lesion with papilloma from the occulted malignancy or ADH by clinical manifestations. Coexisting $\mathrm{AH}$ was also correlated with abnormalities found by ultrasound or microcalcification compared with the benign lesions. It need the professional mammogram and breast ultrasound in clinic.

Evidence supporting the excision of papilloma with $\mathrm{AH}$ is certainly incontrovertible $[21,22]$. The treatment of intraductal papilloma without atypia is controversial and presents the notion, to observe or to excise? Some researchers have advocated that if the radiologic and pathologic results are concordant, regular clinical and radiologic follow-up are safety for the treatment of intraductal papilloma without atypia ${ }^{[23-28]}$, whereas others suggest surgical resection for this group of patients to avoid the possibility of breast cancer ${ }^{[17,29-31]}$. As is known, CNB-proven intraductal papilloma is removed by CNB, either partly or completely. This approach is the diagnostic challenge in papilloma of the breast. The sensitivity of CNB was based on the complete removal of the representative sampling of the target and thus was partly insufficient. A larger core needle biopsy sample can identify breast papillary lesions and can identify patient that do not need surgical resection. With CNB, Shamonki $\mathrm{J}$ et al reported that they identified 51 patients with benign papilloma without atypia who subsequently had surgical resection ${ }^{[32]}$. A total of $11.7 \%(6 / 51)$ of those who had excision revealed ADH, DCIS or invasive carcinoma near the papilloma. Amon $g$ the malignant cases, one excision showed DCIS within the residual papilloma, one excision showed DCIS within the ducts surrounding the papilloma and within an immediately adjacent $0.15 \mathrm{~cm}$ invasive carcinoma, and one excision revealed $A D H$ within the excised papilloma with an adjacent incidental $0.1 \mathrm{~cm}$ tubular carcinoma. These results indicate that excision of a larger tissue sample with 
CNB can significantly improve the predictive value for benign lesions. Several investigators reported that papillary lesions sampled with larger vacuum-assisted excision (VAE) have lower upgrade rates and it is suggested that surgical resection may not be necessary in many of these cases ${ }^{[33-35]}$. VAE provided a method with 9 or 11 needles to obtain more tissue than an automated large-core biopsy device usually that has a 14-gauge needle ${ }^{[36-38]}$. Research from Korea found that the US $14 G$ automated core needle biopsy (ACNB) has a higher false-negative rate and histological upgrading rate in the diagnosis for papillary breast lesions than US-guided VAE ${ }^{[34]}$. Kim SY et al point out that for asymptomatic benign papilloma, if it has benign or low suspicious ultrasound features or imaging is consistent with pathology, it does not need to be resected immediately and can be followed up ${ }^{[33]}$. The researchers included 197 women, of whom 230 cases of asymptomatic benign papilloma were diagnosed by ultrasound-guided CNB and, if necessary, immunohistochemical staining. A total of 144 women underwent surgery, 86 of whom had a VAE and after the benign VAE results all the patients were followed-up for at least 12 months. 86 women treated with VAE were followed up for an average of 26.3 \pm 10.3 months (mean range 12 to 46 months). No sign of malignant tumor was found in the same quadrant. Nayak A points out that conservative treatment may be more appropriate for women diagnosed papilloma by CNB with adequate sampling and precise pathological/radiological correlation, especially those who have received $V A B$ treatment. ${ }^{[23]}$. When the patient has symptoms or lesions greater than 1.5 $\mathrm{cm}$, the recommended surgical indications include pathological / radiological inconsistencies or ultrasound-guided CNB sampling without vacuum assistance.

Intraductal papilloma can be single or multiple, located around the breast and can be found occasionally on imaging ${ }^{[39,40]}$. A study has shown that for the treatment of benign intraductal solitary papilloma diagnosed by CNB, instead of mandated surgical resection, clinical follow-up can be selected when the imaging results are consistent and there are no related high-risk lesions or concurrent malignant tumors in the same quadrant. ${ }^{[24]}$. This study is important for the research on solitary intraductal papillomas. A question that remains is how to determine solitary or multiple intraductal papillomas, whether by sonography, pathology or both. Clinically, multiple papilloma is defined as the presence of at least five distinct independent papillomas in a segment of breast tissue, usually around or under the areola. ${ }^{[2,41]}$. In ultrasound, solitary papilloma can be seen as an independent mass in the dilated mammary duct, a cystic or solid mass with a clear boundary. ${ }^{[41,42]}$. Yi W et al confirmed single papilloma by ultrasound, ${ }^{[43]}$ and Zhu $Y$ et al defined it with a histopathologic diagnosis of solitary intraductal papilloma ${ }^{[44]}$. Clinically, there are discordant conclusions between sonography and pathology. Our study was limited, owing to the vague definition regarding solitary or multiple intraductal papillomas. We did not distinguish the papilloma by the solitary or multiple lesion criteria.

What are the recommendations for papillomas, or the intermediated risk lesions? The intraductal papilla of the breast represents a series of lesions, the pathological basis of which is the proliferation of intraductal epithelium and myoepithelial cells, covering the fibrous vascular stalk. For the diagnostically 
challenging intraductal papilloma with limited sampling via CNB, all papillary lesions should be resected for definite diagnosis. The entire lesion may need to be evaluated to exclude occult AH or malignancy. Therefore, the surgical excision is clearly justified. If the completely removed intraductal papilloma lesions with large VAE are confirmed by radiologic and pathologic findings, a strict clinical follow-up is essential. The discordance between pathology and radiology leads to the upgrade rate of malignancy as well as unnecessary surgical incision. In the future, it is time for an integration of radiology and pathology. In our research, ultrasound was a very useful tool in the preoperative evaluation of breast papilloma and its coexisting lesions, and mammography was powerful for small nodules or clusters of microcalcifications. For an asymptomatic patient with intracystic hypoechoic lesions as seen by ultrasound, a reexamination one month later is suggested to eliminate intracystic deposits. It is obvious that any improvements to resolving the discordance between radiology and pathology and to ensure the timely exchange of clinical features could reduce false negative results and unnecessary surgical excision. Further studies investigating papilloma are needed.

\section{Declarations}

\section{Disclosure}

Only the abstract of our manuscript (A retrospective observational study of intraductal breast papilloma and its coexisting lesions: a real-world experience) had been submitted to 2018 ASCO meeting (Abstract No: e13558), it is publication-only abstracts. The whole manuscript had not been submitted to other journals.

\section{Competing interests}

The authors declared that they have no competing interests.

\section{Authors' contributions}

$\mathrm{XM}$ and HW wrote the manuscript. CF and YG collected the data. CF and XM analyzed the data. FJ and CF supervised the research.

\section{Ethics statement}

The clinicopathological features of each case was reviewed carefully. Informed consent was exempted due to the retrospective format of this study before 2011 .

All the patients who were selected in this research signed an informed consent form for the agreement of participation in this research and for the publication of the results. The research was reviewed and approved by the Ethics Committee of China Medical University and the No.1 Hospital of China Medical University. 


\section{Acknowledgements}

This work was supported by the National Natural Science Foundation of China (No. 81201886 \& 81773163). The funders had no role in study design, data collection and analysis, decision to publish, or preparation of the manuscript.

\section{References}

[1] Rakha EA, Ellis IO. Diagnostic challenges in papillary lesions of the breast. Pathology. 2018. 50(1): 100-110.

[2] Guray M, Sahin AA. Benign breast diseases: classification, diagnosis, and management. Oncologist. 2006. 11(5): 435-49.

[3] Nakhlis F, Ahmadiyeh N, Lester S, Raza S, Lotfi P, Golshan M. Papilloma on core biopsy: excision vs. observation. Ann Surg Oncol. 2015. 22(5): 1479-82.

[4] Collins LC, Schnitt SJ. Papillary lesions of the breast: selected diagnostic and management issues. Histopathology. 2008. 52(1): 209.

[5] Tran HT, Mursleen A, Mirpour S, Ghanem O, Farha MJ. Papillary Breast Lesions: Association with Malignancy and Upgrade Rates on Surgical Excision. Am Surg. 2017. 83(11): 1294-1297.

[6] Karadeniz E, Arslan S, Akcay MN, Subaşi ID, Demirci E. Papillary Lesions of Breast. Chirurgia (Bucur). 2016. 111(3): $225-9$.

[7] MacGrogan G, Tavassoli FA. Central atypical papillomas of the breast: a clinicopathological study of 119 cases. Virchows Arch. 2003. 443(5): 609-17.

[8] Tavassoli FA. Lobular and ductal intraepithelial neoplasia. Pathologe. 2008. 29 Suppl 2: 107-11.

[9] Tavassoli FA. Breast pathology: rationale for adopting the ductal intraepithelial neoplasia (DIN) classification. Nat Clin Pract Oncol. 2005. 2(3): 116-7.

[10] Sakai T, Makita M, Akiyama F, et al. Intraductal papilloma with bloody discharge from Montgomery's areolar tubercle examined by ductoscopy from the areola. Breast Cancer. 2006. 13(1): 104-6.

[11] Shiino S, Tsuda H, Yoshida M, et al. Intraductal papillomas on core biopsy can be upgraded to malignancy on subsequent excisional biopsy regardless of the presence of atypical features. Pathol Int. 2015. 65(6): 293-300.

[12] Kibil W, Hodorowicz-Zaniewska D, Popiela TJ, Szpor J, Kulig J. Mammotome biopsy in diagnosing and treatment of intraductal papilloma of the breast. Pol Przegl Chir. 2013. 85(4): 210-5. 
[13] Ahmadiyeh N, Stoleru MA, Raza S, Lester SC, Golshan M. Management of intraductal papillomas of the breast: an analysis of 129 cases and their outcome. Ann Surg Oncol. 2009. 16(8): 2264-9.

[14] Renshaw AA, Derhagopian RP, Tizol-Blanco DM, Gould EW. Papillomas and atypical papillomas in breast core needle biopsy specimens: risk of carcinoma in subsequent excision. Am J Clin Pathol. 2004. 122(2): 217-21.

[15] Wilson R, Kavia S. Comparison of large-core vacuum-assisted breast biopsy and excision systems. Recent Results Cancer Res. 2009. 173: 23-41.

[16] Youk JH, Kim EK, Kim MJ, Lee JY, Oh KK. Missed breast cancers at US-guided core needle biopsy: how to reduce them. Radiographics. 2007. 27(1): 79-94.

[17] Puglisi F, Zuiani C, Bazzocchi M, et al. Role of mammography, ultrasound and large core biopsy in the diagnostic evaluation of papillary breast lesions. Oncology. 2003. 65(4): 311-5.

[18] Al HT, Delli FP, El-Khoury M, Joseph L, Zheng J, Mesurolle B. Accuracy of percutaneous core needle biopsy in diagnosing papillary breast lesions and potential impact of sonographic features on their management. J Clin Ultrasound. 2013. 41(1): 1-9.

[19] Mercado CL, Hamele-Bena D, Oken SM, Singer Cl, Cangiarella J. Papillary lesions of the breast at percutaneous core-needle biopsy. Radiology. 2006. 238(3): 801-8.

[20] Wen X, Cheng W. Nonmalignant breast papillary lesions at core-needle biopsy: a meta-analysis of underestimation and influencing factors. Ann Surg Oncol. 2013. 20(1): 94-101.

[21] Donaldson AR, McCarthy C, Goraya S, et al. Breast cancer risk associated with atypical hyperplasia and lobular carcinoma in situ initially diagnosed on core-needle biopsy. Cancer. 2017 .

[22] Hartmann LC, Degnim AC, Santen RJ, Dupont WD, Ghosh K. Atypical hyperplasia of the breast-risk assessment and management options. N Engl J Med. 2015. 372(1): 78-89.

[23] Nayak A, Carkaci S, Gilcrease MZ, et al. Benign papillomas without atypia diagnosed on core needle biopsy: experience from a single institution and proposed criteria for excision. Clin Breast Cancer. 2013. 13(6): 439-49.

[24] Swapp RE, Glazebrook KN, Jones KN, et al. Management of benign intraductal solitary papilloma diagnosed on core needle biopsy. Ann Surg Oncol. 2013. 20(6): 1900-5.

[25] Linda A, Zuiani C, Furlan A, et al. Nonsurgical management of high-risk lesions diagnosed at core needle biopsy: can malignancy be ruled out safely with breast MRI. AJR Am J Roentgenol. 2012. 198(2): 272-80.

[26] Carder PJ, Garvican J, Haigh I, Liston JC. Needle core biopsy can reliably distinguish between benign and malignant papillary lesions of the breast. Histopathology. 2005. 46(3): 320-7.

[27] Agoff SN, Lawton TJ. Papillary lesions of the breast with and without atypical ductal hyperplasia: can we accurately predict benign behavior from core needle biopsy. Am J Clin Pathol. 2004. 122(3): 440-3. 
[28] Rosen EL, Bentley RC, Baker JA, Soo MS. Imaging-guided core needle biopsy of papillary lesions of the breast. AJR Am J Roentgenol. 2002. 179(5): 1185-92.

[29] Glenn ME, Throckmorton AD, Thomison JB, Bienkowski RS. Papillomas of the breast 15 mm or smaller: 4-year experience in a community-based dedicated breast imaging clinic. Ann Surg Oncol. 2015. 22(4): 1133-9.

[30] Fu CY, Chen TW, Hong ZJ, et al. Papillary breast lesions diagnosed by core biopsy require complete excision. Eur J Surg Oncol. 2012. 38(11): 1029-35.

[31] Tseng HS, Chen YL, Chen ST, et al. The management of papillary lesion of the breast by core needle biopsy. Eur J Surg Oncol. 2009. 35(1): 21-4.

[32] Shamonki J, Chung A, Huynh KT, Sim MS, Kinnaird M, Giuliano A. Management of papillary lesions of the breast: can larger core needle biopsy samples identify patients who may avoid surgical excision. Ann Surg Oncol. 2013. 20(13): 4137-44.

[33] Kim SY, Kim EK, Lee HS, et al. Asymptomatic Benign Papilloma Without Atypia Diagnosed at Ultrasonography-Guided 14-Gauge Core Needle Biopsy: Which Subgroup can be Managed by Observation. Ann Surg Oncol. 2016. 23(6): $1860-6$.

[34] Kim MJ, Kim SI, Youk JH, et al. The diagnosis of non-malignant papillary lesions of the breast: comparison of ultrasound-guided automated gun biopsy and vacuum-assisted removal. Clin Radiol. 2011. 66(6): 530-5.

[35] Shin HJ, Kim HH, Kim SM, et al. Papillary lesions of the breast diagnosed at percutaneous sonographically guided biopsy: comparison of sonographic features and biopsy methods. AJR Am J Roentgenol. 2008. 190(3): 630-6.

[36] Preibsch H, Baur A, Wietek BM, et al. Vacuum-assisted breast biopsy with 7-gauge, 8-gauge, 9-gauge, 10-gauge, and 11-gauge needles: how many specimens are necessary. Acta Radiol. 2015. 56(9): 1078-84.

[37] Youk JH, Kim EK, Kwak JY, Son EJ. Atypical papilloma diagnosed by sonographically guided 14-gauge core needle biopsy of breast mass. AJR Am J Roentgenol. 2010. 194(5): 1397-402.

[38] Pfleiderer So, Brunzlow H, Schulz-Wendtland R, et al. Two-year follow-up of stereotactically guided 9-G breast biopsy: a multicenter evaluation of a self-contained vacuum-assisted device. Clin Imaging. 2009. 33(5): 343-7.

[39] Georgian-Smith D, Lawton TJ. Controversies on the management of high-risk lesions at core biopsy from a radiology/pathology perspective. Radiol Clin North Am. 2010. 48(5): 999-1012.

[40] Lewis JT, Hartmann LC, Vierkant RA, et al. An analysis of breast cancer risk in women with single, multiple, and atypical papilloma. Am J Surg Pathol. 2006. 30(6): 665-72.

[41] Debnath D, Al-Okati D, Ismail W. Multiple Papillomatosis of Breast and Patient's Choice of Treatment. Patholog Res Int. 2010. 2010: 540590 .

[42] Muttarak M, Lerttumnongtum P, Chaiwun B, Peh WC. Spectrum of papillary lesions of the breast: clinical, imaging, and pathologic correlation. AJR Am J Roentgenol. 2008. 191(3): 700-7.

Page $11 / 22$ 
[43] Yi W, Xu F, Zou Q, Tang Z. Completely removing solitary intraductal papillomas using the Mammotome system guided by ultrasonography is feasible and safe. World J Surg. 2013. 37(11): 2613-7.

[44] Zhu Y, Zhang S, Liu P, Lu H, Xu Y, Yang WT. Solitary intraductal papillomas of the breast: MRI features and differentiation from small invasive ductal carcinomas. AJR Am J Roentgenol. 2012. 199(4): 936-42.

[45] Kil WH, Cho EY, Kim JH, Nam SJ, Yang JH. Is surgical excision necessary in benign papillary lesions initially diagnosed at core biopsy. Breast. 2008. 17(3): 258-62.

[46] Rizzo M, Lund MJ, Oprea G, Schniederjan M, Wood WC, Mosunjac M. Surgical follow-up and clinical presentation of 142 breast papillary lesions diagnosed by ultrasound-guided core-needle biopsy. Ann Surg Oncol. 2008. 15(4): $1040-7$.

[47] Bernik SF, Troob S, Ying BL, et al. Papillary lesions of the breast diagnosed by core needle biopsy: 71 cases with surgical follow-up. Am J Surg. 2009. 197(4): 473-8.

[48] Jaffer S, Nagi C, Bleiweiss IJ. Excision is indicated for intraductal papilloma of the breast diagnosed on core needle biopsy. Cancer. 2009. 115(13): 2837-43.

[49] Cheng TY, Chen CM, Lee MY, et al. Risk factors associated with conversion from nonmalignant to malignant diagnosis after surgical excision of breast papillary lesions. Ann Surg Oncol. 2009. 16(12): 3375-9.

[50] Jung SY, Kang HS, Kwon Y, et al. Risk factors for malignancy in benign papillomas of the breast on core needle biopsy. World J Surg. 2010. 34(2): 261-5.

[51] Youk JH, Kim EK, Kwak JY, Son EJ, Park BW, Kim SI. Benign papilloma without atypia diagnosed at US-guided 14-gauge core-needle biopsy: clinical and US features predictive of upgrade to malignancy. Radiology. 2011. 258(1): 81-8.

[52] Chang JM, Han W, Moon WK, et al. Papillary lesions initially diagnosed at ultrasound-guided vacuum-assisted breast biopsy: rate of malignancy based on subsequent surgical excision. Ann Surg Oncol. 2011. 18(9): 2506-14.

[53] Rozentsvayg E, Carver K, Borkar S, Mathew M, Enis S, Friedman P. Surgical excision of benign papillomas diagnosed with core biopsy: a community hospital approach. Radiol Res Pract. 2011. 2011: 679864.

[54] Rizzo M, Linebarger J, Lowe MC, et al. Management of papillary breast lesions diagnosed on core-needle biopsy: clinical pathologic and radiologic analysis of 276 cases with surgical follow-up. J Am Coll Surg. 2012. 214(3): 280-7.

[55] Jakate K, De Brot M, Goldberg F, Muradali D, O'Malley FP, Mulligan AM. Papillary lesions of the breast: impact of breast pathology subspecialization on core biopsy and excision diagnoses. Am J Surg Pathol. 2012. 36(4): 544-51.

[56] Lu Q, Tan EY, Ho B, Chen JJ, Chan PM. Surgical excision of intraductal breast papilloma diagnosed on core biopsy. ANZ J Surg. 2012. 82(3): 168-72.

[57] Kim WH, Chang JM, Moon WK, et al. Intraductal mass on breast ultrasound: final outcomes and predictors of malignancy. AJR Am J Roentgenol. 2013. 200(4): 932-7.

Page $12 / 22$ 
[58] Foley NM, Racz JM, Al-Hilli Z, et al. An International Multicenter Review of the Malignancy Rate of Excised Papillomatous Breast Lesions. Ann Surg Oncol. 2015. 22 Suppl 3: S385-90.

[59] Boufelli G, Giannotti MA, Ruiz CA, et al. Papillomas of the breast: factors associated with underestimation. Eur J Cancer Prev. 2017 .

[60] Niinikoski L, Hukkinen K, MHK L, Ståhls A, Meretoja TJ. Breast Lesion Excision System in the diagnosis and treatment of intraductal papillomas - A feasibility study. Eur J Surg Oncol. 2018. 44(1): 59-66.

\section{Tables}

TABLE 1 The clinical characteristics of 4450 intraductal papilloma patients with surgical excision 


\begin{tabular}{|c|c|c|c|c|}
\hline characteristics & $\mathrm{n}$ & $\begin{array}{l}\text { Pure papilloma or with non-malignancy } \\
\qquad \mathrm{n}=3633\end{array}$ & $\begin{array}{l}\text { With malignancy } \\
\qquad \mathrm{n}=817\end{array}$ & $p$-value \\
\hline je, mean (SD) & 4450 & $45.70 \pm 11.19$ & $53.73 \pm 12.63$ & $F=280.65$ \\
\hline & & $(13-88)$ & $(25-86)$ & $P<0.05$ \\
\hline pple discharge & & & & $x 2=0.29$ \\
\hline Yes & 1638 & 1344 & 294 & $p>0.59$ \\
\hline No & 2812 & 2289 & 523 & \\
\hline ith palpable mass & & & & $x^{2}=644.02$ \\
\hline Yes & 2290 & 1542 & 748 & $p<0.01$ \\
\hline No & 2160 & 2091 & 69 & \\
\hline pple discharge and mass concurrently & & & & $x^{2}=158.68$ \\
\hline Yes & 732 & 477 & 255 & $p<0.01$ \\
\hline No & 3718 & 3156 & 562 & \\
\hline trasonic abnormality & & & & $x 2=28.27$ \\
\hline Yes & 4405 & 3610 & 795 & $p<0.01$ \\
\hline No & 45 & 23 & 22 & \\
\hline traductal hypoechoic by ultrasonic & & & & $x 2=1.09$ \\
\hline Yes & 2361 & 1941 & 420 & $p>0.05$ \\
\hline No & 2089 & 1692 & 397 & \\
\hline mormality by ultrasonic $n=4405$ & & & & $\chi 2=1537.89$ \\
\hline BIRADS4A & 3015 & 2872 & 143 & $p<0.01$ \\
\hline BIRADS4B & 911 & 619 & 292 & \\
\hline BIRADS4C or 5 & 479 & 119 & 360 & \\
\hline ammographic distortion $n=3938$ & & & & $x 2=315.73$ \\
\hline Yes & 1256 & 793 & 463 & $p<0.01$ \\
\hline No & 2682 & 2348 & 334 & \\
\hline crocalcification $n=3938$ & & & & $\chi 2=1198.17$ \\
\hline Yes & 569 & 147 & 422 & $p<0.01$ \\
\hline No & 3369 & 2994 & 375 & \\
\hline
\end{tabular}

TABLE 2 The clinical characteristics of 3633 intraductal papilloma patients with coexisting benign or atypical lesions with surgical excision 


\begin{tabular}{|c|c|c|c|c|}
\hline characteristics & $\mathrm{n}$ & $\begin{array}{l}\text { Pure papilloma or with benign } \\
\qquad n=1973\end{array}$ & $\begin{array}{l}\text { With AH or LCIS } \\
\qquad n=1660\end{array}$ & p-value \\
\hline ye, mean (SD) & 3633 & $44.01 \pm 10.50$ & $47.77 \pm 11.50$ & $F=92.61$ \\
\hline pple discharge & & $(13-81)$ & $(15-88)$ & $\begin{array}{c}p<0.05 \\
x 2=6.48\end{array}$ \\
\hline Yes & 1344 & 693 & 651 & \multirow[t]{2}{*}{$0.01<p<0.05$} \\
\hline No & 2289 & 1280 & 1009 & \\
\hline ith palpable mass & & & & $x^{2}=1.10$ \\
\hline Yes & 1542 & 853 & 689 & \multirow[t]{2}{*}{$p>0.05$} \\
\hline No & 2091 & 1121 & 971 & \\
\hline ipple discharge and mass concurrently & & & & $x^{2}=0.36$ \\
\hline Yes & 477 & 253 & 224 & \multirow{2}{*}{$p>0.05$} \\
\hline No & 3156 & 1720 & 1436 & \\
\hline traductal hypoechoic by ultrasonic & & & & $x^{2}=0.07$ \\
\hline Yes & 1941 & 1058 & 883 & \multirow[t]{2}{*}{$p>0.05$} \\
\hline No & 1692 & 915 & 777 & \\
\hline Jnormality by ultrasonic $n=4405$ & & & & $x^{2}=1537.89$ \\
\hline BIRADS4A & 2872 & 1711 & 1161 & \multirow[t]{3}{*}{$p<0.01$} \\
\hline BIRADS4B & 619 & 199 & 420 & \\
\hline BIRADS4C or 5 & 119 & 50 & 69 & \\
\hline ammographic distortion n=3141 & & & & $x^{2}=0.58$ \\
\hline Yes & 793 & 415 & 378 & \multirow{2}{*}{$p>0.05$} \\
\hline No & 2348 & 1192 & 1156 & \\
\hline icrocalcification n=3938 & & & & $\chi 2=21.14$ \\
\hline Yes & 147 & 48 & 99 & \multirow[t]{2}{*}{$p<0.01$} \\
\hline No & 2994 & 1559 & 1435 & \\
\hline
\end{tabular}

TABLE 3 The coexisting breast lesions of intraductal papillomas: A selected literature review 


\begin{tabular}{|c|c|c|c|c|}
\hline \multirow[t]{3}{*}{ Reference } & \multirow[t]{3}{*}{ cases } & \multicolumn{3}{|c|}{ Excision findings } \\
\hline & & Nonconcomitant or with benign $\mathrm{n}(\%)$ & With atypical & With malignant \\
\hline & & & $\mathrm{n}(\%)$ & $\mathrm{n}(\%)$ \\
\hline Mercado $\mathrm{CL}^{[19]}$ & 36 & $26(72.22 \%)$ & $8(22.22 \%)$ & $2(5.56 \%)$ \\
\hline Kil WH $^{[45]}$ & 76 & $62(81.58 \%)$ & $5(6.58 \%)$ & $9(11.84 \%)$ \\
\hline Rizzo M ${ }^{[46]}$ & 169 & $109(64.50 \%)$ & $19(11.24 \%)$ & $41(24.26 \%)$ \\
\hline Bertnik SF [47] & 71 & $30(42.25 \%)$ & $22(30.99 \%)$ & $19(26.76 \%)$ \\
\hline Jaffer S ${ }^{[48]}$ & 104 & $87(83.65 \%)$ & $8(7.69 \%)$ & $9(8.65 \%)$ \\
\hline Ahmadiyeh N [13] & 69 & $28(40.58 \%)$ & $31(44.93 \%)$ & $10(14.49 \%)$ \\
\hline Sohn YM ${ }^{[49]}$ & 39 & $36(92.21 \%)$ & $3(7.69 \%)$ & $0(0 \%)$ \\
\hline Jung SY [50] & 160 & $141(88.12 \%)$ & $9(5.62 \%)$ & $10(6.25 \%)$ \\
\hline Youk JH ${ }^{[51]}$ & 160 & $143(89.38 \%)$ & $9(5.63 \%)$ & $8(5.0 \%)$ \\
\hline Chang JM ${ }^{[52]}$ & 60 & $46(76.67 \%)$ & $12(20.2 \%)$ & $2(3.33 \%)$ \\
\hline Rozentsvavg E ${ }^{[53]}$ & 67 & $54(80.60 \%)$ & $8(11.94 \%)$ & $5(7.46 \%)$ \\
\hline Rizzo M ${ }^{[54]}$ & 276 & 197(71.38\%) & $42(15.22 \%)$ & $37(13.41 \%)$ \\
\hline Jakate $\mathrm{K}^{[55]}$ & 162 & $90(55.56 \%)$ & $38(23.46 \%)$ & $34(20.99 \%)$ \\
\hline Lu Q ${ }^{[56]}$ & 106 & $69(69.09 \%)$ & $25(23.58 \%)$ & $12(11.32 \%)$ \\
\hline Fu CY ${ }^{[30]}$ & 280 & $174(62.14 \%)$ & $72(25.71 \%)$ & $34(12.14 \%)$ \\
\hline Al Hassan T ${ }^{[18]}$ & 130 & $90(69.23 \%)$ & $23(17.69 \%)$ & $17(13.08 \%)$ \\
\hline Chang JM ${ }^{[57]}$ & 64 & $55(85.94 \%)$ & $7(10.94 \%)$ & $2(1.56 \%)$ \\
\hline Glenn ME [29] & 179 & $114(63.69 \%)$ & $43(24.02 \%)$ & $22(12.29)$ \\
\hline Nakhlis F [3] & 97 & $42(43.30 \%)$ & $41(42.27 \%)$ & $14(14.43 \%)$ \\
\hline Foley NM ${ }^{[58]}$ & 238 & $156(65.55 \%)$ & $37(15.55 \%)$ & $45(18.91 \%)$ \\
\hline Boufelli G ${ }^{[59]}$ & 85 & $80(94.12 \%)$ & $0(0 \%)$ & $5(5.88 \%)$ \\
\hline Niinikoski L [60] & 28 & $25(89.29 \%)$ & $2(7.14 \%)$ & $1(3.57 \%)$ \\
\hline Tran HT ${ }^{[5]}$ & 58 & $43(74.24 \%)$ & $10(17.24 \%)$ & $5(8.62 \%)$ \\
\hline Total & 2990 & $2094(70.03 \%)$ & $516(17.26 \%)$ & $238(12.71 \%)$ \\
\hline
\end{tabular}


concomitant lesions of breast $78.31 \%(3485 / 4450)$ without concomitant

$19.10 \%(850 / 4450)$

Benign
$25.24 \%(1122 / 4450)$

\section{$\mathrm{ADH}+\mathrm{ALH}+\mathrm{LCIS}$ $37.30 \%(1660 / 4450)$}

Malignancy $18.36 \%(817 / 4450)$

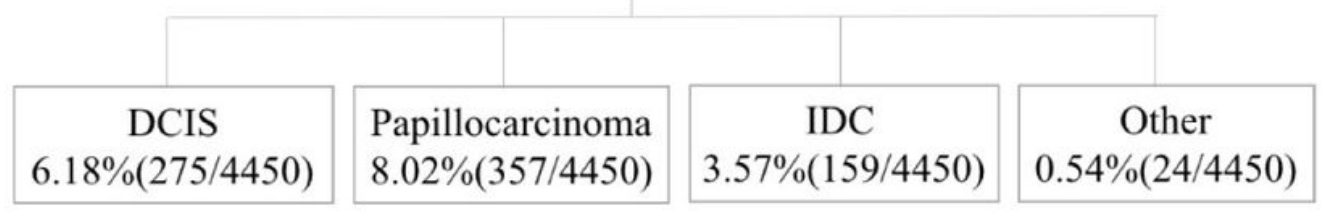

\section{Figure 1}

The papilloma and its coexisting breast lesions. This chart indicated that a total of $18.36 \%(817 / 4450)$ of intraductal breast papilloma coexisted with malignant lesions of the breast, $37.30 \%(1660 / 4450)$ coexisted with AH (including ADH and ALH), 25.24\% (1123/4450) coexisted with benign lesions, and only $19.10 \%(850 / 4450)$ coexisted without concomitant lesions. 

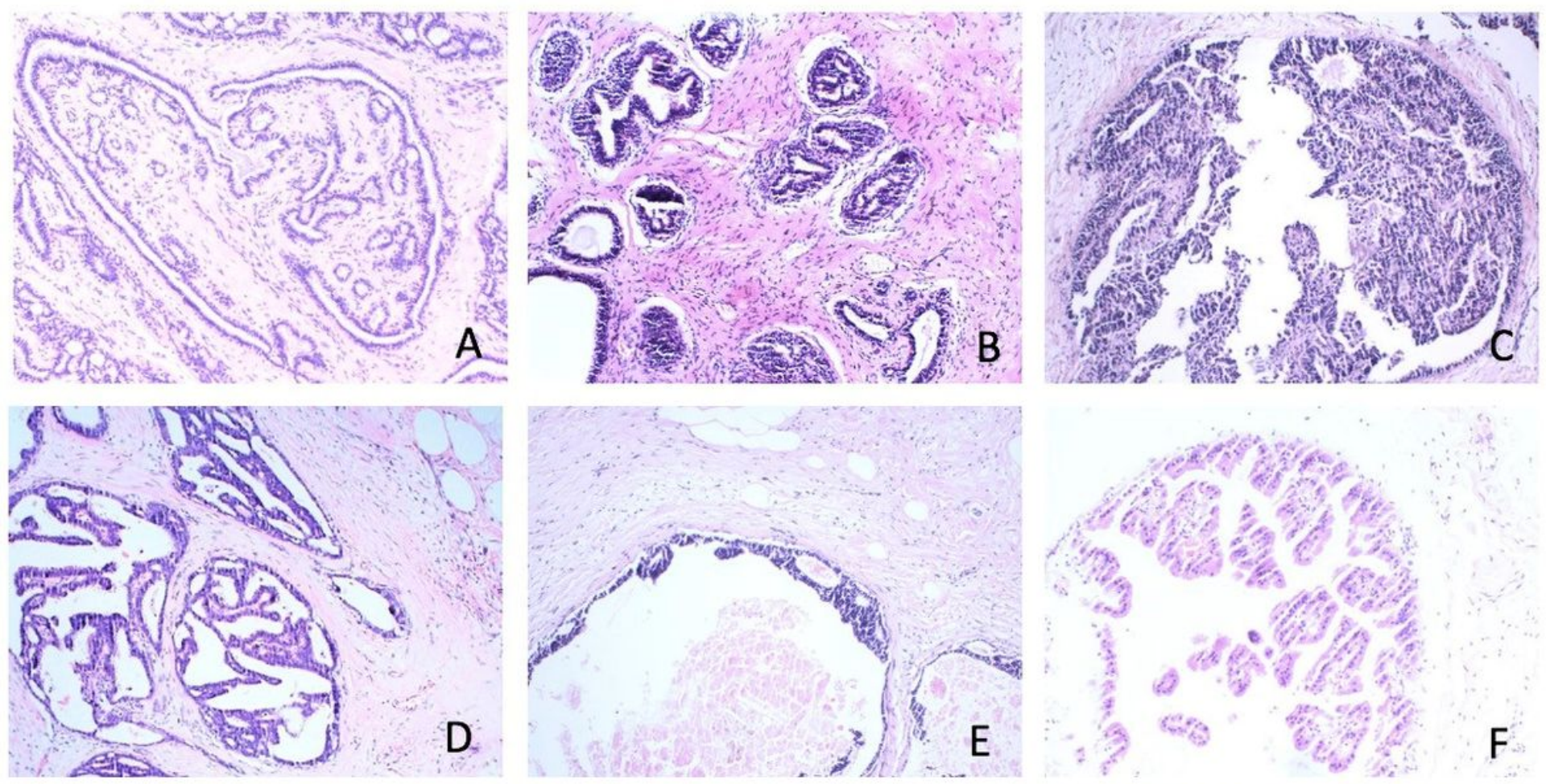

$\mathrm{F}$
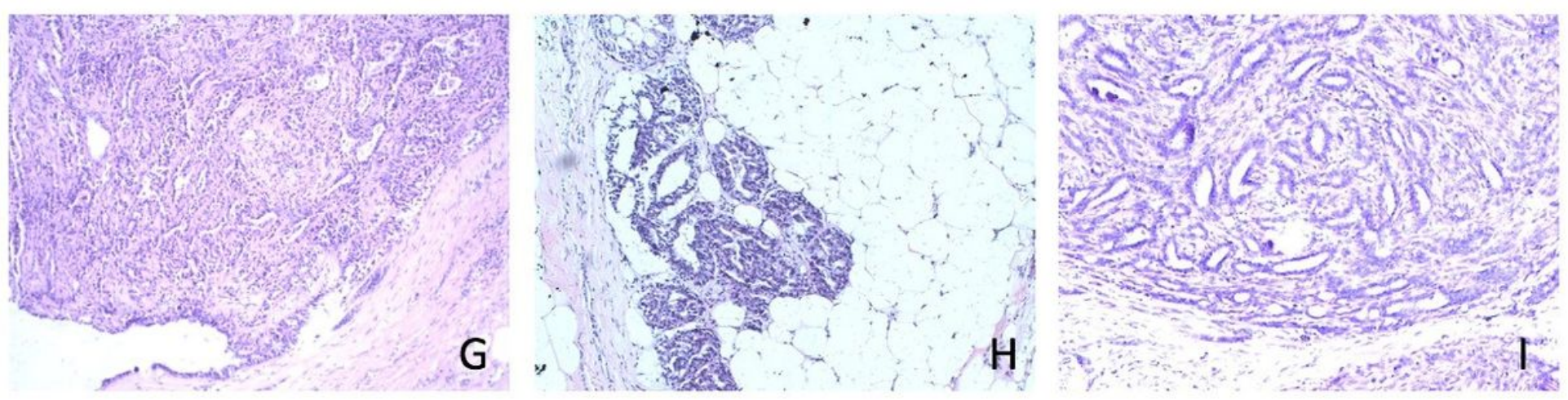

\section{Figure 2}

The papilloma and its coexisting benign lesions. (A-C) pure papilloma. (D) papilloma and its coexisting usual ductal hyperplasia. (E) papilloma and ductal ectasia. (F) papilloma and apocrine metaplasia. (F) papilloma and fibroadenoma. $(\mathrm{G})$ infarcted papilloma. $(\mathrm{H})$ papilloma and adenomyoepithelial adenosis. (I) papilloma with simple epithelium and complex glands. 

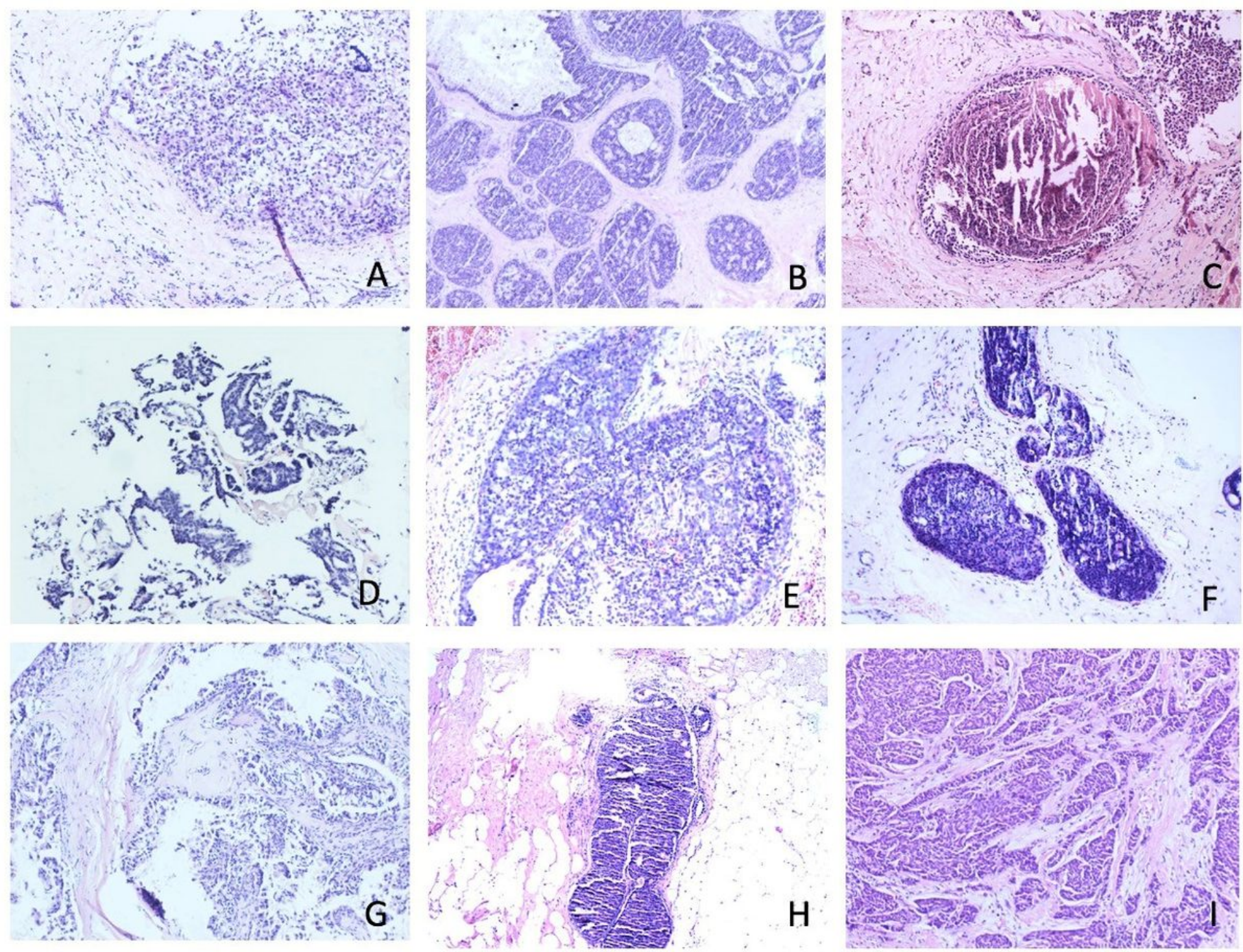

\section{Figure 3}

The papilloma and its coexisting ductal carcinoma in situ. 

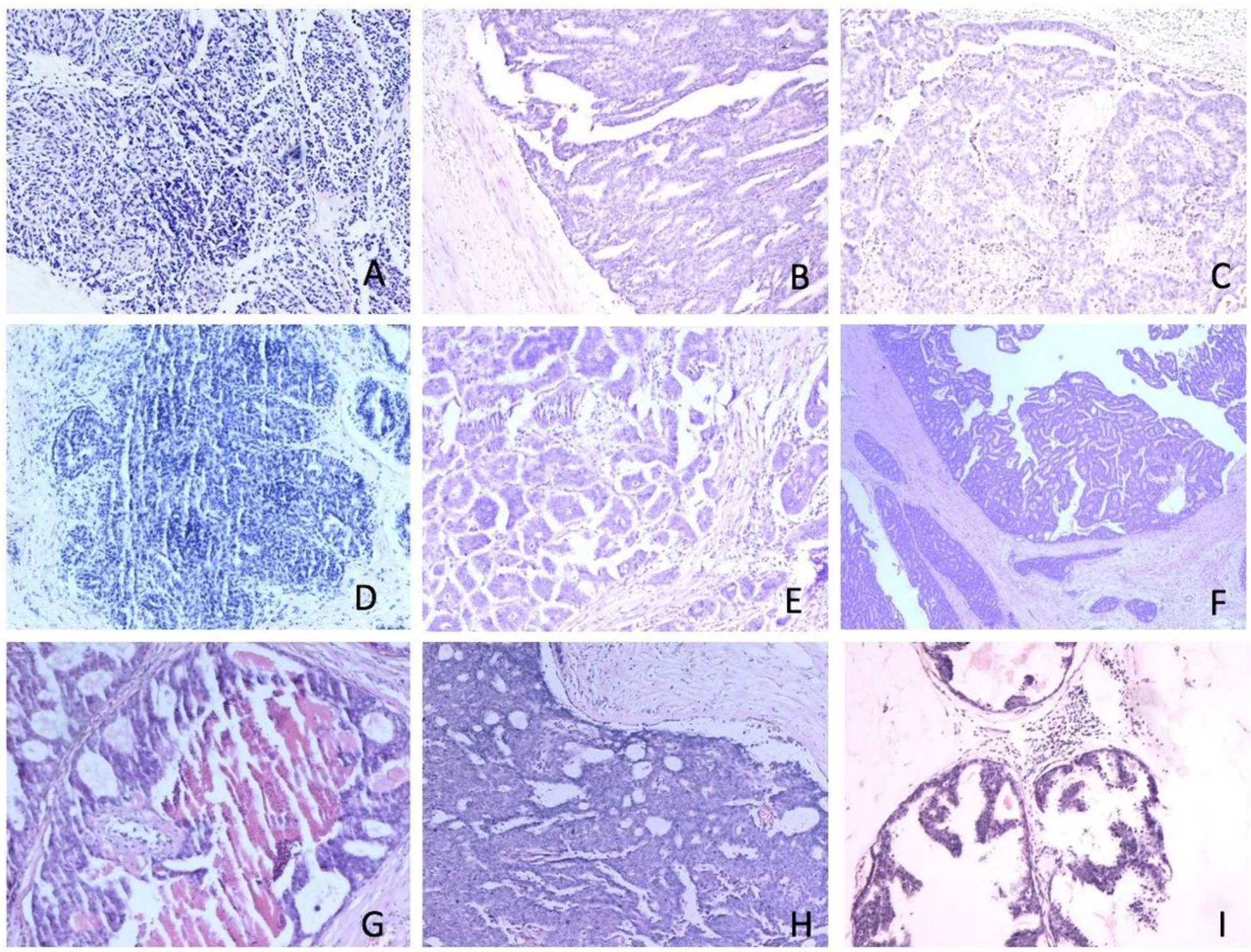

Figure 4

Papillocarcinoma. 

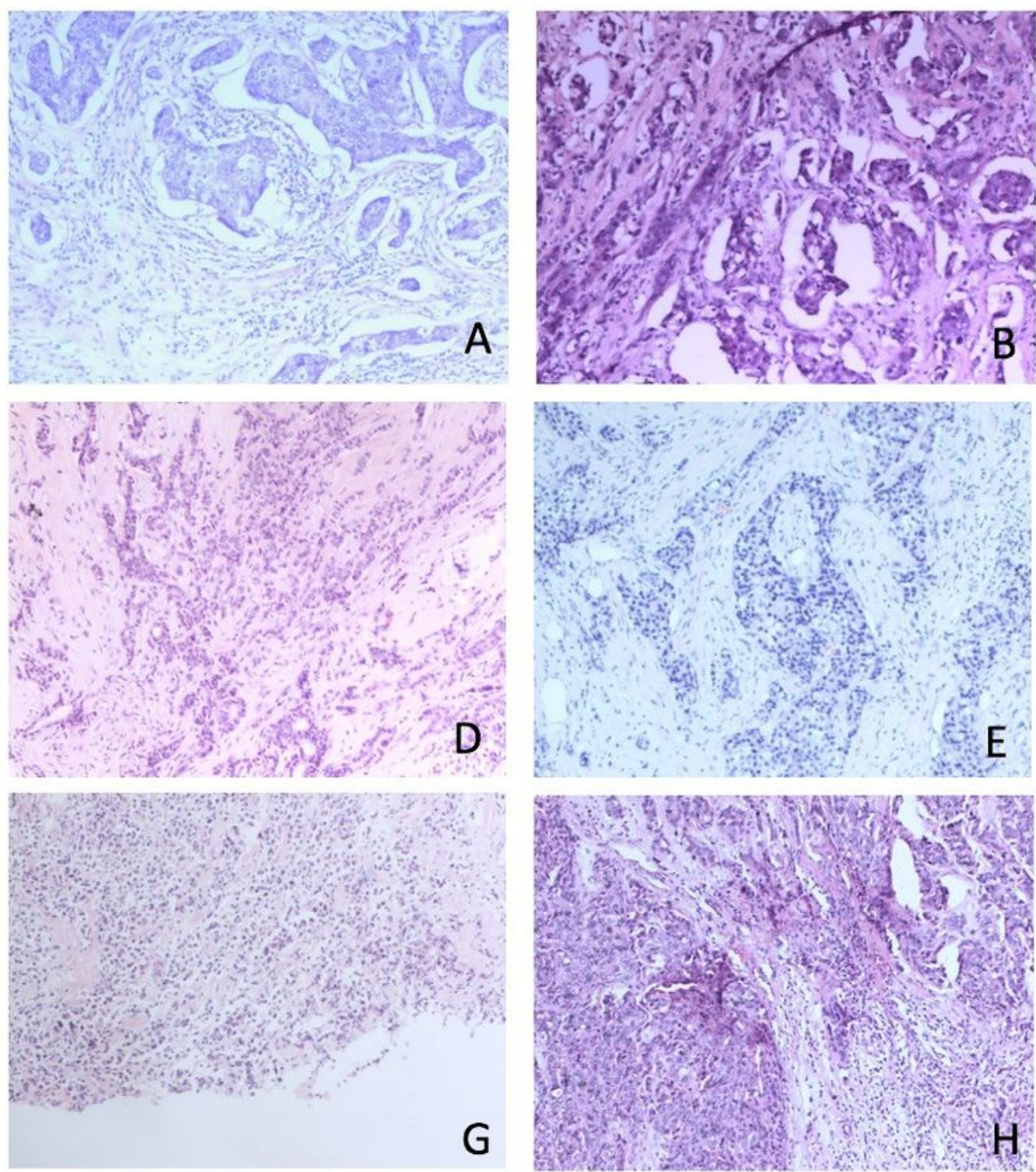
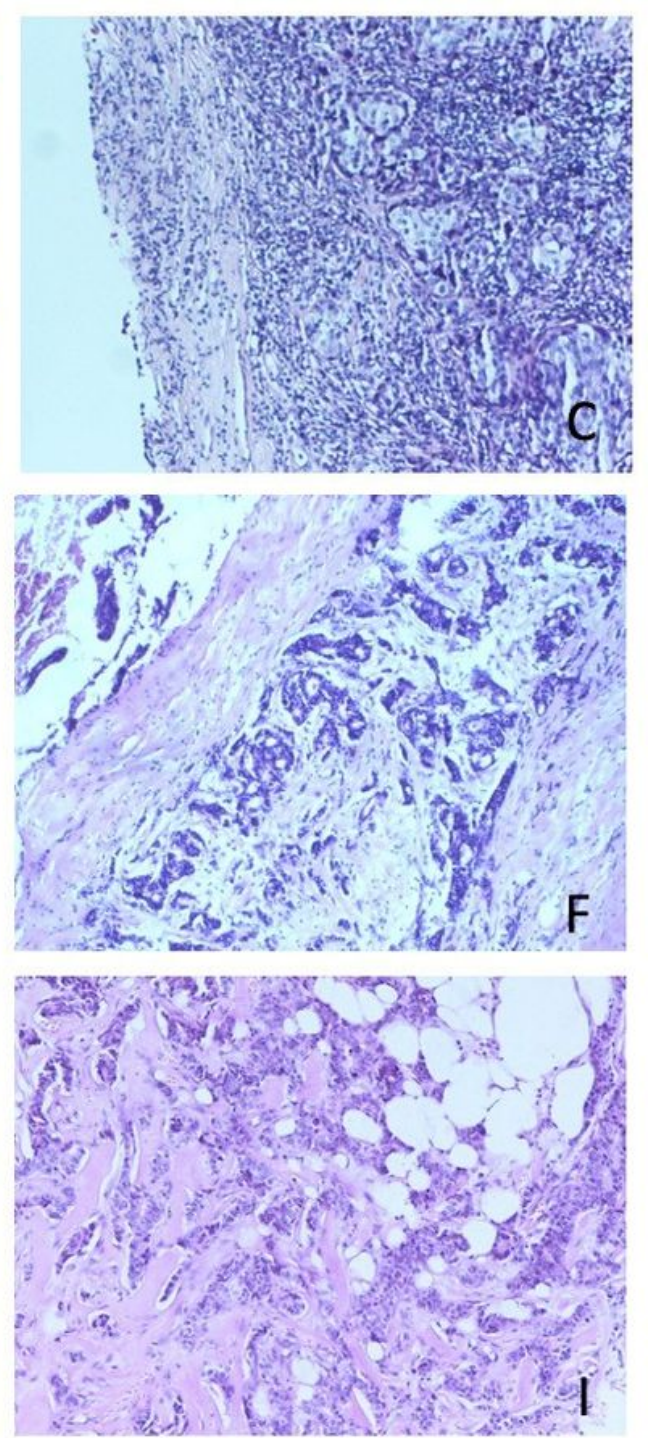

\section{Figure 5}

The papilloma and its coexisting invasive ductal carcinoma. 


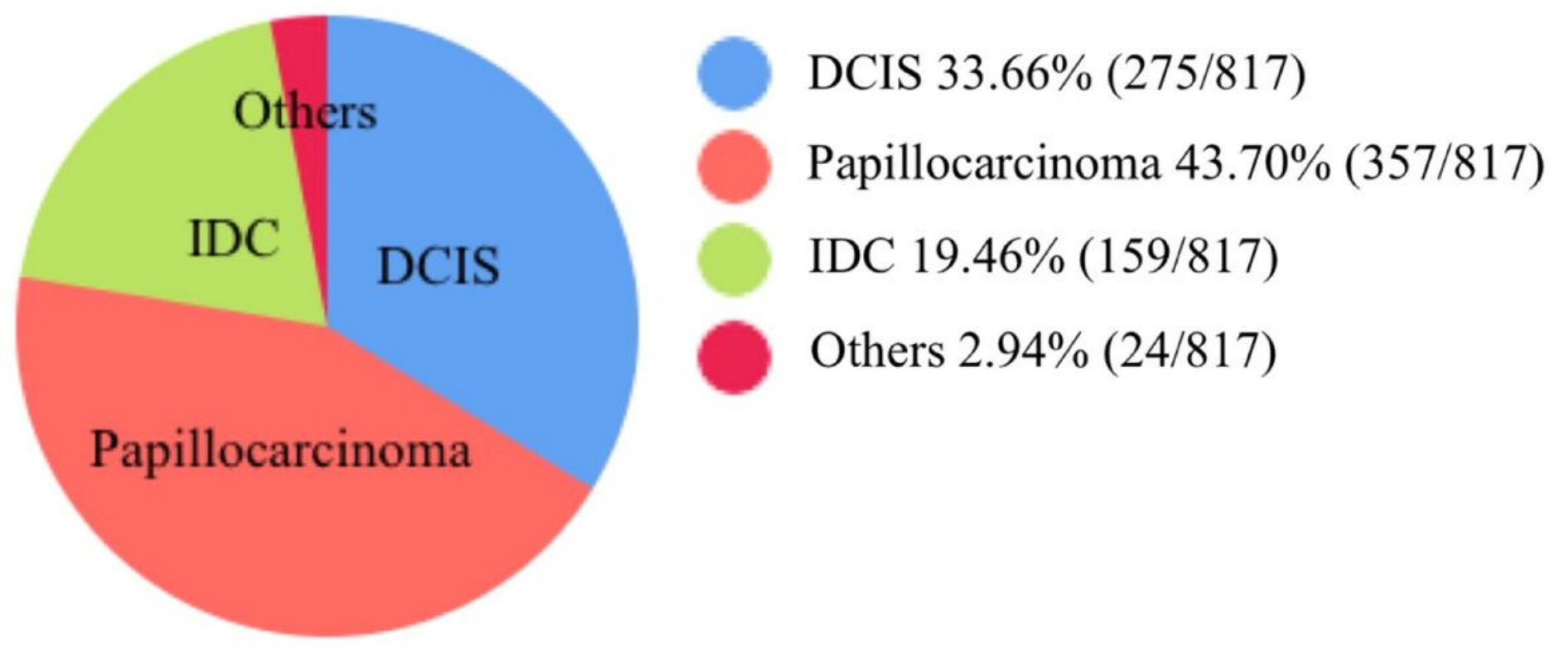

Figure 6

The coexisting malignancy of papilloma. This chart explained that $43.7 \%(357 / 817)$ were papillocarcinoma, 33.66\% (275/817) were DCIS, 19.46\% (159/817) were invasive ductal cancer of the breast and $2.94 \%$ (24/817) were another type in the concomitant malignancy of intraductal breast papilloma. 